\title{
ACRE, JURUÁ E PURUS: ÁREAS DIALETAIS DO ATLAS ETNOLINGUÍSTICO DO ACRE
}

Luísa Galvão Lessa (UFAC) luisa_lessa@uol.com.br

\section{Introdução}

O presente trabalho é uma contribuição ao Atlas Etnolinguístico do Acre- ALAC. Com esse propósito, faz-se um levantamento da linguagem de homens e mulheres envolvidos no mundo da seringa, objetivando descrever a oralidade regional, com a feitura de cartas léxicas e fonéticas, em fronteiras dialetais, identificando a unidade e a diversidade linguística. Esta atividade irá assegurar, para a posteridade, dados riquíssimos que podem vir a se perder no tempo, à medida que o homem muda de hábitos e entra em contato com outras culturas. O estudo lexical foi realizado a partir dos inquéritos pertencentes a três Áreas de Pesquisa do Projeto ALAC: Vale do Acre, Vale do Juruá e Vale do Purus. Nestas áreas, observou-se o comportamento dos falantes do sexo masculino e feminino, na faixa etária C (36 a 80 anos), para demarcação de fronteiras dialetais, representadas em mapas, gráficos e tabelas, nas Zonas de Pesquisa: Rio Branco.

Rio Branco (RB), Plácido de Castro (PC) e Xapuri (XA); Tarauacá (TA), Feijó (FE) e Cruzeiro do Sul (CS); Sena Madureira (SM), Manuel Urbano (MU) e Assis Brasil (AB). Trabalhou-se com dezoito inquéritos, observando o uso dos substantivos, verbos, adjetivos e advérbios terminados em -mente. Nestas classes de palavras, observou-se as conservações e as inovações linguísticas, que foram distribuídas em 17 campos semânticos, deles resultando a feitura do glossário ZONAS DIALETAIS NA AMAZONIA - CARTAS LÉXICAS E FONÉTICAS. RESULTADOS E CONCLUSÕES: Consta-se a forte presença dos substan- 


\section{FACULDADE DE FORMAÇÃO DE PROFESSORES}

tivos e dos verbos. Aqueles, por nomearem as coisas do mundo e estes, por traduzirem as ações do fazer humano no mundo. Os adjetivos e advérbios terminados em - mente foram pouco utilizados, o que denota a pouca atenção dessa comunidade em atribuir qualidade e em circunstanciar as ações no tempo. E com relação à unidade, diversidade, inovação e conservação, tem-se: nos verbos, a unidade e conservação nas Zonas pesquisadas, pois os informantes, tanto os do sexo feminino quanto os do masculino, não divergem no uso dessa classe de palavra. Com relação aos substantivos, observa-se o maior número da diversidade: o objeto escada apresenta variação terminológica, ora é escada, ora mutá ou trepes$s a$, nas Zonas de CS e AB, com informantes do sexo feminino. Tem-se, então, escada $=$ mutá $=$ trepessa; buião e bulhão, a primeira ocorrência em CS e a segunda em PC; fornalha e fornaia, sendo a primeira em RB, MU, FE, TA e a segunda em SM, XA; cabrita e faca de seringa para o mesmo objeto) "os hábitos da vida moderna tem uma ação niveladora", e, segundo Lessa (1998) "é urgente a recolha da linguagem regional, sob pena de se perderem muitas palavras com o desaparecimento dos objetos e das mudanças de hábitos e costumes". Portanto, é importante que se faça um registro imediato de termos que poderão se perder através dos anos, em decorrência das modificações por que passam a vida do homem acreano.

A linguagem sofre variações que traduzem a forma de vida do homem, assim diz Carlota e Ferreira (1994)

[...] que os falantes de uma mesma língua, mas de regiões distintas, tem características linguísticas diversificadas e se pertencem a uma mesma região também não falam da mesma maneira, tendo em vista os diferentes estratos sociais e as circunstâncias diversas da comunicação. (CARLOTA; FERREIRA, 1994, p. 12)

E ainda, Nascentes (1957) "O Brasil é constituído por uma rede dialetal, onde há unidade na diversidade e diversidade na unidade”.

Então, percebe-se, que é por meio da língua que o homem mostra as suas concepções e as de sua comunidade. Em virtude disso expressa Hjelmslev (Apud LESSA, 2003)

A linguagem é o instrumento graças ao qual o homem modela o seu pensamento, seus sentimentos, suas emoções, seus esforços, sua vontade e seus atos, o instrumento graças ao qual ele influencia e é influenciado, a base última e mais profunda da sociedade humana.

Enfim, percebe-se uma relação muito estreita entre o homem seringueiro e as palavras, visto que a utilização dessa ou daquela palavra depende de sua necessidade, o falante faz uso do conhecido para deno- 
minar o desconhecido. Assim sendo cada palavra tem sempre uma razão de ser, um motivo que justifique o seu emprego.

\section{Objetivos}

- Fornecer dados linguísticos para contribuir com um melhor conhecimento da linguagem acreana;

- Estudar o falar das comunidades no Vale do Acre, Juruá e Purus, observando os traços de unidade e diversidade linguística;

- Observar o caráter variável da língua, que a língua muda conforme a Zona de Pesquisa, faixa etária e sexo do informante.

\section{Materiais e métodos}

Utilizam-se computacionais aplicados à Geografia linguística e trabalharam-se quatorze inquéritos distribuídos entre os Vales do Acre, Juruá e Purus, em ambos os sexos, na faixa-etária C (36 a 80 anos).

No Vale do Acre, trabalhou-se com quatro inquéritos, sendo dois informantes do sexo feminino e dois do sexo masculino em cada zona de pesquisa. No Juruá, investigaram-se cinco inquéritos, dois de Feijó, um do sexo masculino e outro do sexo feminino, em Tarauacá também dois informantes de ambos os sexos e em Cruzeiro do Sul um informante do sexo masculino. No Vale do Purus, a pesquisa concentrou-se em Manuel Urbano, com um informante do sexo feminino, em Assis Brasil tomaram-se dois informantes também de ambos os sexos e com Sena Madureira se procedeu da mesma forma que em Manuel Urbano.

Realizou-se, então, o levantamento de itens lexicais dos inquéritos, cujos dados foram organizados nos seguintes campos semânticos:

1) Palavras relativas ao trabalho do seringueiro com a seringa;

2) Palavras relativas aos utensílios utilizados pelo seringueiro para o corte;

3) Palavras relativas à estrada de seringa;

4) Palavras relativas ao corte da seringa;

5) Palavras relativas à comercialização da borracha;

6) Palavras relativas às pessoas envolvidas com o trabalho da seringa; 
7) Palavras relativas aos meses, estações do ano e fases da lua propícia ou não para extração do látex.

\section{Pressupostos teóricos}

A presente pesquisa seguiu os caminhos trilhados pela dialetologia social, geografia linguística, bem como os ensinamentos da lexicologia, lexicografia, semântica e da linguística geral. Também partiu dos conceitos de alguns teóricos como Ferreira e Cardoso (1995, p. 11) [...] "Uma língua é um conjunto de sinais acústico- orais, que funciona na intercomunicação de uma coletividade. É resultado de um processo histórico, evolutivo"; e por isso não podemos estudar o homem sem estudar sua língua, porque a língua reflete cultura; e no dizer de Cunha (1988, p. 29) "A língua tem que ser atual, porque é expressão de vida". "A estagnação, já o dissemos é a morte do idioma. A história de uma língua é justamente a história de suas inovações". É por isso que se tem urgência em coletar esses dados linguísticos e registrá-los em documentos escritos para assegurar ao futuro a história da vida atual.

Já Cunha (1988, p. 79) [...] E em linguística a unidade não é incompatível com a variedade, antes a pressupõe. Nenhuma língua permanece uniforme em todo o seu domínio, e ainda num só local apresenta um sem_ número de diferenciações de maior ou menor amplitude". Observase isso, ao estudar a linguagem dos vales do Acre, Juruá e Purus que além de existir unidade entre as Zonas, também é possível verificar diversidade entre as Zonas, faixas-etárias e o sexo dos informantes. Portanto, é como diz Nascentes (1957) "O Brasil é constituído por uma rede dialetal, onde há unidade na diversidade e diversidade na unidade".

Diz Lessa (1997, p. 5) "A língua de um povo, como se sabe, é a resultante do conjunto das variedades linguísticas existentes". Está comprovado, cientificamente, o fato de que o maior número possível de informações sobre tais variedades linguísticas, quer regionais, quer sociais, contribuirá para o melhor conhecimento da língua e, consequentemente, do homem". Em virtude disso, é notório a importância desse estudo, pois podemos conhecer e analisar os hábitos, costumes, lendas e crendices do homem acreano, ou seja o seu universo. 


\section{Resultados e discussões}

A pesquisa empreendida com quatorze informantes teve como intuito adentrar no universo de cada um deles, permitindo o desvendamento de suas vidas, da sua linguagem, costumes, crendices, religião, trabalho e as experiências de vida.

De acordo com a descrição e a análise do léxico utilizado nos três Vales, Acre Juruá e Purus, constatou-se ser possível descrever o ser humano por meio de suas palavras, pois não se pode separar o seringueiro de seu mundo físico-social. A linguagem traduz esse mundo e as palavras estão intimamente ligadas às necessidades presentes no cotidiano de suas vidas. Assim, o seringueiro está sempre utilizando palavras conhecidas para denominar o desconhecido. Além do mais, cada palavra tem sempre um motivo que justifica o seu emprego, que está aliado aos fatores da vida, ocasionando, com isso, a variação de uso de uma ou outra forma, de acordo com o lugar, a faixa etária e o sexo do informante.

Para melhor compreensão da diversidade de usos da linguagem, faz-se uma análise comparativa diatópica, diafásica e diastrática, observando o comportamento linguístico dos falantes nas Zonas de Pesquisa de Rio Branco (RB), Plácido de Castro (PC) e Xapuri (XA); Tarauacá (TA), Feijó (FE) e Cruzeiro do Sul (CS); Sena Madureira (SM), Manuel Urbano (MU) e Assis Brasil (AB), na faixa-etária C.

Observou-se nos substantivos leite, balde, querosene, camin, diNêro e comboêro, como já se esperava, unidade e conservação nas Zonas de Tarauacá, Feijó, Rio Branco, Xapuri e Sena Madureira. Além da unidade lexical, verificou-se uma diversidade de natureza fonética. Ocorre que alguns informantes tanto do sexo feminino quanto do sexo masculino ora trocam fonemas, ora acrescentam ou suprimem vogais ou consoantes, tanto nas Zonas de Assis Brasil , como Manuel Urbano, Cruzeiro do Sul, Feijó , Rio Branco e Plácido de Castro, conforme os exemplos: gente > ente > rente; leite > lete; meio > mei; cortando.

Ainda, com relação à diversidade, observa-se que apenas os falantes do sexo masculino nas Zonas de Sena Madureira, Manuel Urbano e Feijó utilizaram as lexias jirau e pé de burro para denominar um estrado de varas que é utilizado pelo seringueiro para cortar a árvore na parte mais alta. Têm-se, aqui, dois significantes que nomeiam o mesmo objeto, uma espécie de escada. 


\section{FACULDADE DE FormaÇÃo de PROFESSORES}

E em relação ao substantivo escada, verifica-se diversidade quanto à denominação, ora aparecendo mutá ou trepessa nas Zonas de Cruzeiro do Sul e Assis Brasil, com informantes do sexo feminino. Tem-se, então: escada $=$ mutá $=$ trepessa .

Percebe-se a diversidade também entre as palavras bandera e pano, pois só dois informantes, um do sexo masculino de Assis Brasil e o outro do sexo feminino de Feijó utilizaram a lexia pano para denominar a parte da seringueira onde se faz o corte na madeira. Os demais informantes falam bandera. Então, aqui, tem-se dois significantes para um mesmo significado.

Observa-se que tanto os informantes do sexo feminino quanto os do sexo masculino utilizaram as lexias rancho, comida e boia para denominar a alimentação. Essas palavras estão presentes nas Zonas de Rio Branco, Plácido de Castro, Sena Madureira, Manuel Urbano, Tarauacá e Cruzeiro do Sul, mas somente o informante do sexo masculino de Rio Branco falou boia.

Quanto à inovação, verificou-se outro fator linguístico, que um informante do sexo feminino, Zona de Plácido de Castro, utilizou os quatro substantivos: caba, cara, camarada e rapaiz como gíria para denominar o seringueiro. E um informante do sexo masculino de Xapuri para dialogar com a documentadora utiliza a forma de tratamento madame. Temse, aqui, como formas de tratamento: rapaiz, caba, cara, camarada, madame. São palavras que utilizam ora como substantivos, ora como formas de tratamento.

Tem-se o seguinte quadro colhido nos sete campos semânticos estudados:

\subsection{Palavras relativas ao trabalho com a seringa:}

Borracha - Sf. Denominação dada à substância elástica feita do látex da seringueira. Apresenta-se em forma de uma bola, com furo ao centro, pesando entre 10 a 25 quilos.

(...) nosso patrão aviava nóis pó ... pó ... cada fim de mêis

... todos os mêis ia dexá aquela mercadoria ... se tiNa produto isso bem ... se tiNa a ...

borracha trazia né ... se num tiNa ficava pó próximo mêis (...)

AB138 CM:04

(...) tiNa o patrão.... aí o camboêro viNa... ela marcarra o dia de i pa mage... aí lá ela fa-

zia... lá o camboêro levarra aquela borracha todiNa (...)

AB137 CF: 12.

(...) não vendia só a borracha só mermo

RB131CF:01 


\section{DEPARTAMENTO DE LETRAS}

Borracha em bola - Sf. Denominação dada ao formato da borracha defumada em oposição à borracha de prancha.

... rachava o cavaco botarra dento tocava o fogo fazia fumaça e ... fazia borracha em bola ...

PC184CF:06

Borracha em prancha - Sf. Denominação dada à borracha coagulada a borracha em pracha é o seguinte... a gente coloca né... traiz o leite... coloca ele pra coalhá... TA087CM:09

Bulhão - Sm. Denominação dada ao forno feito no chão onde se põe o carvão, o cavaco, ou coco, para o processo de defumação da borracha. Variação de fornalha aí ... tiNa aqueles tanque né ... aqueles bulhão assim ...

PC184 CF:06

Buião - Sm. Denominação dada ao forno feito no chão onde se põe o carvão, o cavaco, ou coco, para o processo de defumação da borracha. Variação de bulhão.

cortava... quando chegava fazia o fogo no buião aí ia defuma

CS102CF:52

Cavaco. sm. Pedaço de madeira usado para fazer fogo de fornalha.

(...) quano chegarra em casa aí nóis ia tirá o cavaco (...).

AB 137 CF: 05.

Cernambi - Sm. Espécie de borracha confeccionada com as sobras do leite que coalha no processo da defumação, no momento de banhar a borracha com o látex.

Com cernambi ... aí a rente bota uns pau ... far o fogo ... e aquece o leite XA176 CF:06

... aí quano a rente chegarra c'um oto lête a rente cortarra esse cernambí assim todim... AB137CF:28

Naquele tempo num vendia essa borracha ( )... hoje a borracha é cernambi né MU153CM:103

CTP - sm. Borracha que não é defumada, e sim em formato de prancha.

$\# D$

O que é CTP?

\# L

é... que a borracha num é defumada... feita as pranchiNa

MU151 CF:06

Defuma. v. Ato ou ação de colocar o látex sobre o princípio sobre intensa fumaça. Nesse processo o leite transforma-se em borracha.

só uNa... só dá de defuma uNa que é só uma fornáia né

AB137CF:28

ele ia defumá o lête né...

MU151 CF:03

Cortava... quando chegava o fogo nobuião aí ia defuma

CS102CF:52

Fornaia. sf. Denominação dada ao forno feito no chão onde se põe o carvão, o cavaco, ou coco, para o processo de defumação da borracha. Variação de fornalha.

(...) colocarra dentro d'um saco... o leite(...) aí quando chegarra em casa eles botavo na 


\section{FACULDADE DE FORMAÇÃO DE PROFESSORES}

bacia aí ia fazê fogo na fornaia... aí quano a fornaia tava quente que a fumaça tava quente ele ia defumá a borracha(...)

SM118 CF:26

A fornaia ta ... o fogão ... o ... a fumaça ... aí a gente vai defumano num sabe ...

XA176 CF:07

Fornalha - sf. Espécie de forno usado no defumador para coagular o leite da seringa e transformá-lo em borracha.

só o balde ... e ... e pra ... no tempo ... de primêro ... tiNa o balde ... tiNa a bacia ... tiNa a fornalha $N E$

RB068CM:13

(...) fazia assim uma fornalha no chão né ...

MU151 CF:06

Imprensar -V. Ação de apertar a borracha para que ela fique bem seca.

(...) bota pa qualhá ... aí imprensa

MU151CF: 06

a gente imprensa... a maió parte é imprensada né...

CS 081CM:06

Jirau. sm. Denominação dada ao estrado de varas feito sobre forquilhas cravadas no chão utilizado pelo seringueiro no processo de confecção da borracha de prancha. (...) fazia o jirau que toda cima do fogo do jirau ...

SM117CM: 16

... eles faz jirau ... de madêra ... faz aquele jirau de madêra ...

FE099 CM:18

(...) foi se atrepô num jirau (...).

MU 153 CM: 24.

Leite. sm. Líquido branco e opaco retirado da seringueira.

... se a ente... chega com leite né... aí tem a fornalha...

TA087CM:06

O leite... onde põe?

FE093CF:07

Lete. sm. . Líquido branco e opaco retirado da seringueira.

A tigela... aí a tigela apara aquele lête aí quano é de tarde...

AB137CF:24

É ôtubo... novembo... dezembo... é os mêis bom de lête... janêro

CS102CF:57

Prancha. sf. Borracha feita em prancha, sem defumar.

... ensinaro o pessoal fazê prancha...

FE099 CM:08

hoje é prancha ... a gente faz ...

RB068CM:14

... agora como ... do ... pó ... nei ..pofim não tiNa borracha em bola ... era prancha... PC184 CF:06

Pé de Burro. sm. Denominação dada ao estrado de varas feito sobre forquilhas cravadas no chão utilizado pelo seringueiro no processo de confecção da borracha de prancha. 
uns chama jirau... otos chama pé de burro...

FE099CM:18

Prensa. sf. Recipiente onde a borracha é imprensada.

(...) faiz aquela prensa e coloca a borracha dento ...

MU151CF:06

\subsection{Palavras relativas aos utensílios utilizados pelo seringueiro no corte da seringa:}

Bacia. sf. Recipiente usado para depositar o leite quando vai ser defumado.

(...) arente traiz o leite... despeja na bacia... aí vai defumá borracha(...)

SM118CF:03

... aí chegava ia botá o leite na bacia...

AB138CM:03

(...) aí ia... nóis colocara o lête na bacia (...).

AB 137 CF: 05.

Balde. sm. Utensílio usado na colheita do látex.

\#D

Como era feita a colheita?

\#L

c' um balde... eles faiz aquele balde... a rente chega lá na seringuêra... pega a tigela e... despeja dento do balde...

SM118CF:03

... a rente... vai cortano aí quano chega aqui na boca do oito aí dêxa as cosa... o saco... o balde...

AB137CF:25

aí come aquele poço que a rente leva... aí a rente... aí sai com o balde pa colhe

RB131CF:03

Baldo. sm. Utensílio usado na colheita do látex.

... tem que levantá cedo... quato hora da madrugada pra fazê o seu café... arrumá o seu equipamento de trabalho... a faca... o baldo... o teçado de baiNa...

AB138CM:02

Cabrita. sf. Espécie de faca usada no corte da seringa.

(...) era cabrita pa cortá...

SM118CF:26

era uma cabrita... a lâmina... o balde... e o saco...

SM117CM:03

aí ele pegava a cabrita que é de cortá seringa

PC183 CF:03

Cavadô. sm. Instrumento de madeira usado no defumador para sustentar a borracha no bulinete. Variação de cavado.

A ente tira aquela borracha ..que defumo ...aí pega enrola num ... no pau né que aí ente chama cavado 


\section{FACULDADE DE FormaÇÃo de PROFESSORES}

TA087 CM:06

... mais tem um pau que se chama cavado ...

PC063 CM:22

aí ali uNa ponta do... do... do cavadô que a rente enrolarra a borracha era aquele pau e o ôto era nessa argora que eu tô dizeno

AB137CF:28

Escada. sf. Série de degraus por onde se sobe ou se desce.

Faiz a escada...

PC184 CF:05

uNa escada... é uNa escada... aí a rente corta lá em cima

AB137CF:26

pois bem ... eu tiNa ... eu carregava uNa escada ... escada ... essas escada que tem ...

RB068CM:09

Espingarda. sf. Denominação dada a arma de fogo, usada pelo seringueiro quando vai para o corte para matar animais que lhe servem de alimento.

(...) botarra a boca da espingarda assim(...)

SM118CF:13

Coloca nas costa e a espingarda den... a tiracolo aqui

AB137CF:26

A espingarda ... a faca ...

FE099 CM:07

Faca de seringa. sf. Instrumento afiado e com ponta usado pelo seringueiro para extrair o leite da seringueira.

\#D

o que mais ele levava?

\# L

a faca de seringa né...

MU151CF:03

\#D

com a faca... com a faca de seringa(...)

AB138CM:10

$\# D$

quais os objetos que a senhora levava para cortar?

\#L

a faca de seringa

CS102CF:52

Lamparina.sf. Utensílio usado para iluminar a estrada durante o corte da seringa

A luz é... é a querosene né... lamparina mermo

CS081CM:12

é uNa ... uNa lamparina ... feita de ... alumim...

FE099 CM:02

é uNa lamparina ...

RB968CM:116

LamparinaziNa. sf. Dim. Utensílio usado para iluminar a estrada durante o corte da seringa.

$\# D$

O seu pai saia no escuro? 


\section{DEPARTAMENTO DE LETRAS}

\section{\# L}

era ... ele levava uma poronga ... uma lamparinaziNa na cabeça ...

MU151CF: 03

Poronga. sf. Espécie de lamparina em formato de uma coroa que o seringueiro usa na cabeça para iluminar o caminho à noite.

\#D

o seu pai saía no escuro?

\# L

era ... ele levava uma poronga ... uma lamparinaziNa na cabeça ...

MU151CF: 03

... quem corta de noite leva a poronga né ... que é o fogo

FE099 CM:07

\# D

Como é que chama essa lamparina com espelho?

\# L

poronga

CS081CM:13

ah... levava a faca... o balde... o saco... e a poronga que saia trêis hora da madrugada... levava poronga( )

RB131CF:02

Querosene. sm. Tipo de combustível que mantém a poronga acesa.

A luz é... é a querosene né... lamparina mermo CSO81CM:12

(...) que num precisa fazê a munição ... querosene né ...

MU151CF: 12

Saco. sm. Receptáculo de pano, couro ou material plástico aberto em cima e fechado no fundo e nos lados, utilizado para colocar o látex

era uma cabrita... a lâmina... o balde... e o saco...

SM117CM:03

ah... levava a faca... o balde... o saco... e a porongaque saia treis hora da madrugada... levava poronga( )

RB131CF:02

Teçado de baiNa.sm. Denominação dada ao facão grande.

... tem que levantá cedo... quato hora da madrugada pra fazê o seu café... arrumá o seu equipamento de trabalho... a faca... o baldo... o teçado de baiNa...

AB138CM:02

Tigela. sf. Vasilha que se põe abaixo do golpe dado na seringueira para colher o leite. é: levava a faca faze o corte assim ((gestos))... aquelabandêriNa faiz o corte( )... embote a tigela embaixo do corte

RB131CF:02

... no balde... a gente tira das tigela... das tigela e vô despejano no balde

CS102CF:52

A tigela... aí a tigela apara aquele lête aí quano é de tarde..

AB137CF:24

Trepessa. sf. Espécie de escada rústica, feita em madeira, que o seringueiro usa para cortar a parte superior da seringueira. 


\section{FACULDADE DE FORMAÇÃO DE PROFESSORES}

Trepessa é um pau que a seNora escora...

AB137CF:26

\subsection{Palavras relativas às estradas de seringa:}

Boca da estrada. sf. Início da estrada de seringa.

... quano a rente chega no... na boca da estrada...

AB137CF:26

pois bem... a rente corta... imbute... aí a gente chega lá na boca da estrada... a gente fica ali um pôco né...

RB131CF:03

Aí a rente vai quano chega na boca da estrada

XA176 CF:02

Camin. sm. Denominação dada ao espaço percorrido ou por percorrer a pé, pelo seringueiro. Variação de caminho

Não ...tendo camin ... começava o camin da barraca... abria aquele pique ...

SM117 CM:05

pela merma... pelo mermo camin da manga... aí segue no espigão de novo...

AB137CF:25

... começa esse camin ... justamente ... quando e rente começa do mei do arco ( ) fecha aqui ...

TA087 CM:03

Caminzin. sm. Denominação dada ao espaço percorrido ou por percorrer a pé, pelo seringueiro. Variação de caminho

(...) aqui entra esse caminzin ... aqui tem uma madêra ...

SM118 CF:10

Espigão. sm. Caminho reto que vai da casa do seringueiro até o início da estrada de seringa.

chama os espigão da estrada é

AB137CF:23

posso ...((vozes)) tem esse espigão aqui no fêche a gente vai ... quando chega aqui vem pra casa

CS081 CM:02

espigão grande né ... porque fechava com uma hora de viagem ...

FE099 CM:03

Estrada. sf. Espécie de caminho, no qual estão dispostas as seringueiras.

(...) andarra nas estrada cortano seringa (...).

MU 153 CM: 02.

Nóis chama estrada (...)

AB138 CM:05

estrada ... aí a miNa estrada ... u'a é ... chama-se a boca-da-estrada né ... RB068CM:118

Estrada de Centro. sf. Denominação dada à estrada de seringa que fica distante da casa do seringueiro; fica no centro da mata.

A estrada que fica longe é a estrada de centro

AB137CF:23

Estrada de Porta. sf. Denominação dada à estrada onde o fecho fica perto da casa do 
seringueiro.

Essa que fechava em casa chamava estrada de porta

SM117 CM:05

(...) é a .... estrada de Porta é essas que a rente vem almoçá em casa (...).

AB 137 CF: 04.

Feche. sm. É uma volta completa na estrada de seringa.

Posso ...((vozes)) tem esse espigão aqui no fêche a gente vai ... quando chega aqui vem pra casa

CS081 CM:02

Fecho. sm. É uma volta completa na estrada de seringa.

O fecho é porque a estrada ... vai ... aqui

FE099 CM:03

(...) e lá o fecho da estrada (...)

MU 153 CM: 03

Aí quano a rente... aí a rente volta pro fecho de novo né

AB137CF:26

É o fecho que a rente chama... fecho da estrada

CS102CF:64

Ladera-sf. Denominação dada a uma inclinação de terreno. Variação de ladeira.

Bem ... tem as ladêra né ...

AB138 CM:05

(...) porque aí a perna que a rente vê que tem maise... maise ladêra (...).

$A B$ 137 CF: 07 .

Manga. sf. Pequeno desvio na estrada de seringa onde há árvores fora do rodo da estrada e o seringueiro vai lá, corta e volta pelo mesmo caminho.

... agora aqui que é a manga...

CS102CF:63

(...) aí quando chega naquela manga entra né (...).

AB 137 CF: 05.

Nóis chama manga (...)

AB138CM:06

Oito. sm. Denominação dada, pelo seringueiro, a um pequeno desvio na estrada de seringa onde há árvores fora do rodo da estrada. O seringueiro realiza o corte entrando por um caminho e voltando por outro caminho que, junto com a estrada têm o formato de um oito.

(...) tem o oito (...).

$A B$ 137 CF: 06.

Ahé sim ... o oito vai lá ... e volta aqui ... aí chega aqui e tira direto ... assim

PC184 CF:04

(...) tem oito ... porque a rente vai assim... aí quano chega aqui no ... no rodo aí entra pa perna do oito (...)

SM118 CF:10

Ah ali é o oito que chama

RB131CF:04

Perna da estrada. sf. Lugar referente ao lado direito ou lado esquerdo da estrada de seringa. 


\section{FACULDADE DE FORMAÇÃO DE PROFESSORES}

Onde entra... a ente chama a perna da estrada...

TA087CM:03

Perna direita. sf. $O$ lado direito da estrada de seringa.

Perna direita né ...

TA087 CM:03

(...) tem perna direita né (...).

$A B$ 137 CF: 07.

Perna esquerda. sf. O lado esquerdo da estrada de seringa

Que nóis coNece ... aí já essa que vem pa fecha aqui com essa ((gestos)) aí a gente só ... chama perna... a perna esquerda ... certo

TA087 CM:04

(...) tem a perna esquerda (...).

AB 137 CF: 07.

Rodo. sm. Percurso na estrada de seringa por onde o seringueiro passa primeiro cortando e depois colhendo o leite.

Por exemple a estrada lá é de frente começa aqui e vai dá aquele rodo...

TA087 CM:02

... e vai assim... assim... dá aquele rodo... aí vem bate de novo

RB131CF:04

É... faiz a volta completa da... do rodo...

AB137CF:25

Varadô.sm. Atalho usado pelo seringueiro.

(...) aí ficava aquele varado pra você camiNá

SM117 CM:02

... aí nói ficamo no varadô ...

RB131CF:05

\subsection{Palavras relativas ao corte da seringa:}

Bandera. sf. Forma como o seringueiro risca a seringueira. Variação de bandeira

(...) faiz assim as bandêra aí vai corta os risco...

SM118CF:30

Por pano ô bandêra(...)

AB138CM:12

É riscano o par da madêra (látex) ... nas bandêra num sabe ...

FE093 CF:04

Brocar. v. Ação de cortar o mato para plantar

É broca ... ela fica limpa

TA094 CF:05

Ah ... broca ...toca fogo ... quando num queima bem a gente faiz coivara... toca fogo nas coivara

XA176 CF:18

... aí ele brocarra e derrubarra..

AB137CF:22

Capina. v. Limpar (as plantas, uma plantação, um terreno) de capim ou de qualquer erva.

Variação de capinar. 
(...) chega lá nóis vamo capiná um arroiz (...).

MU 151 CF: 50.

... aí vai pó roçado capina(...)

XA176CF:193

Colher. v. Ato ou ação de retirar os frutos da planta.

aí come aquele pôco que a rente leva... aî rente ai'sai com o balde pa colhê

RB131CF:03

aí ... eu começava a colhê onze hora né ...

RB068CM:117

Colhe... colhe né ... juntá o lête todim ... leva no balde ... bota num saco

XA176 CF:04

Cortar. v. Fazer incisão em; dar um atalho em; abertura superficial feita na casca da seringueira para obtenção do leite.

$\# L$

ajudava ele a corta seringa ...

MU152 CF:02

Ah pa reente... corta assim as madêra tudim

RB131CF:03

Ali era... cortá... na... no seringal do finado Mota

CS102CF:54

Embutir. v. Ato ou ação de fincar a tigela na seringueira para aparar o leite.

e: levava a faca faze o corte assim((gestos))... aquela banderiNa faiz o cotre( )... embote a tigela embaixo do corte

RB131CF:02

( ...) embotia a tigela na madêra ...

SM118 CF:26

(...) e as tigeliNa pa emboti né ...

SM117:03

... a gente vai riscando e embutindo as tigela ...

FE099 CM:04

Limpar. v. Ato ou ação de limpar uma certa parte da estrada.

É broca... ela fica limpa

TA094CF:05

Aí aqueles home vão tudo brocá o roçado... limpá ou apaNiá arroize ou batê palha de

arroize

AB137CF:34

Tem que limpa é...

RB131CF:03

Madera. sf. Árvore grumífera, o mesmo que seringa ou seringueira, de onde é extraído o látex. Variação de madeira.

Ah pa rente... corta as madêra tudim

RB132CF:03

cento e vinte madêra...

FE099 CM:06

rapa a madêra né... assim ((gestos))...

AB137CF:24

Paxiúba. sf. Espécie de madeira utilizada na construção da casa do seringueiro.

Era casa mermo... coberta de ((tosse)) paia... e... e soalho de paxiúba... paxiubão CS102CF:59

A miNa casa era de paxiúba... coberta de palha...

PC184CF:11 


\section{FACULDADE de FormaÇÃo de PROFESSORES}

A miNa casa era feita de paxiúba mermo... de palha AB137CF36

Raspar. v. Ato ou ação de limpar a seringueira, tirar a casca grossa que existe sobre ela. Variação de raspar.

...aí em março a rente rá tá terminando de roçá aí rapa ... aí abril rá pa começa a corta AB137CF:43

Aí... que depois de rapá é que vai corta

CS102CF:57

Risco. sm. Traço que o seringueiro dá na madeira para extrair o leite.

é o risco mermo... é o risco mermo (..)

AB138 CM:11

é um pedaço de pau assim deste tamaNe com um ferro com lâmina incima pa dá o risco PC184 CF:03

aí a rente vai corta o primêro né... aí vai cortano costadim do ôto... cortano... cortano... até quano finda aquela... aquela... aquela bandêra

AB137CF:24

Roçar. v. Ato ou ação de fazer a estrada, limpando todo o excesso de mato.

(...) eu só fazia colhê e roçava a estrada mar meu padrasto(...)

SM118 CF:02

aí um ajudava o ôto a roçá...

SM117 CM:16

A gente começa primêramente roça as estrada...

CS081CM:01

é ... agora o ôtro vai aculá e roçando ... alimpando o camim ... supono mêo assim ... como ...

RB068CM:04

Seringa. sf. Denominação dada à árvore da qual se extrai o látex; seringueira; madeira.

Pá emboti na seringa pa apara o leite(...)

AB138CM:10

...aí ele pegava a cabrita que é de cortá seringa

PC184CF:03

é...porque é longe e corta muita seringa... e vaicolhê... aí vai se espalhano...

TA087CM:02

Seringuera. sm. Árvore da família das euforbiáceas, cujo leite dele se fabrica o látex para a fabricação da borracha.

(...) às veiz até dzentos metro d'uma seringuêra pra ôta

AB138CM:06

A seringuêra... rapa a seringuêra

AB137CF:24

\subsection{Palavras relativas à comercialização da borracha}

Balança. sf. Instrumento com que se determina ou a massa ou o peso dos corpos.

(...) aí ia coloca em cima da balança...

MU151CF:12

Comprar. v. Adquirir por dinheiro; ganhar, adquirir ou obter com sacrifício ou prejuízo material ou moral.

Eu vendia lá... eu vendia... vendia lá pó pessoal que comprava

CS102CF:54

Eu comprava... o meu patrão era o Abidãozin... que eu comprava 


\section{DEPARTAMENTO DE LETRAS}

MU153CM:129

hoje em dia ... hoje em dia é ... comprá tudo na cidade né ...

RBD68CM:25

DiNero. sm. Mercadoria (geralmente representada por células e moedas), que tem curso oficial, e cujo valor é estabelecido como equivalente que permite a troca por outras mercadorias.

... cinco dia hoje tô queimano no carvão porque num teNo diNero pó gás...

PC184CF:29

Eu nunca consegui diNêro não

MU153CM:114

é .... pois é ... hoje em dia a borracha tá dano diNeiro ... e no mês todo num dá nada né RBD68CM:26

Mercadoria. sf. Gêneros de um modo geral que chegam nos seringais.

Bom... lá num era muito bom não né... porquê... falta assim das coisa né... mercadoria RB131CF:01

O seringueiro da floresta veve... passando muita necessidade... falta de mercadoria...

CS081CM:01

dava... aí ele comprarra mercadoria...

XA176CF:14

Sindicato. sm. Associação de operários de uma classe para defesa de seus interesses profissionais.

(...) aí depois que fundo o sindicato

MU151CF:11

Vender. v. Trocar por dinheiro.

Eu vendia lá... eu vendia... vendia lá pó pessoal que comprava

CS102CF:54

...o meu irmão cortava... aí levava pa marge... pa vende a borracha

XA176CF:14

Não vendia só a borracha só mermo

RB131CF:01

Eu vendia pó meus patrão... aqui no Purus

MU153CM:113

\subsection{Palavras relativas às pessoas envolvidas com o trabalho da se- ringa}

Comboêro. sm. Diz-se do homem que transporta mercadoria, inclusive a borracha. Variação de comboieiro.

Lá tem... os patrão manda busca né... tem os camboiero né... que carrega... vai dexá mercadoria

FE099CM:11

(...) tiNa o patrão.... aí o camboêro viNa... ela marcarra o dia de i pa mage... aí lá ela fazia... lá o camboêro levarra aquela borracha todiNa (...)

$A B 137 C F: 12$.

o... o camboêro viNa... viNa faze a nossa... leva por metade... metade pa tanto... metade pa... mercadoria

RB131CF:01

Marretêro. sm. Comprador ilegal da borracha, comprador clandestino. Variação de marreteiro.

Marretêro... regatão... chama regatão 


\section{FACULDADE DE FORMAÇÃO dE PROFESSORES}

FE099CM:14

Marretêro... aí vê um marretêro aí a rente vende

XA176CF:07

Vende... a gente vende pro marretêro

FE093CF:07

Matêro. sm. Pessoa contratada pelo patrão para abrir caminho nas estradas para o corte da seringa.

É o matêro... eles que faiz a estrada

FE093CF:04

...aí foi... foi... o patrão q'eu trabalhava com ele saiu...

TA087CM:10

Matêro... sabê fazê uma estrada tem que te um matêro...

PC063CM:07

é o matêro ... chama-se matêro ...

RB068CM:21

Patrão. sm. Chefe ou proprietário de estabelecimento em relação aos empregados; empregador, dono do barracão.

(...) eu vendia pó meus patrão (...)

MU 153 CM: 15.

TiNa o patrão... aí o camboêro viNa...

AB137CF:29

...aí foi... foi... o patrão q'eu trabalhava com ele saiu...

TA087CM:10

Regatão.sm. Vendedor ou comprador que percorre os rios de barco parando de lugar em lugar.

(...) tem esse negoço de regatão que vem pela bêra do rie

SM117CM:08

Marretêro... regatão... chama regatão

FE099CM:14

O regatão... um que anda no rie vendeno

FE093CF:08

Seringuêro. sm. Individuo que se dedica á extração do látex da seringueira e com ele prepara a borracha.Variação de seringueiro.

... o seringuêro sempre corta uma estrada grande e ôta pequena

MU153CM:104

O seringuêro da floresta veve... passando muita necessidade... falta de mercadoria...

CS081CM:01

\subsection{Palavras relativas aos locais onde se realizam as atividades do látex.}

Barracão. sm. Casa de moradia do dono do seringal ou de seu administrador, e que é, ao mesmo tempo, habitação, depósito de gêneros de primeira necessidade, da borracha colhida nos centros, e loja para a venda de gêneros, roupas, ferramentas e utensílios.

(...) pode trazê tudo pó barracão

MU151CF:17

(...) tiNa as sua casa... seu barracão de... da que eles trabalhavo (...)

AB138CM:05 
... o ... lá no barracão pa podê tira ele ...

RB131CF:05

Colocação. sf. Parte da divisão do seringal; área destinada ao seringueiro para seu trabalho na seringa.

... eu teNo nove colocação que dá o apelido... quase um seringalzim é

PC063CM:06

Só... depois que saí.. daquela colocação...

TA087CM:04

Era...às veiz tiNa causo... colocação que é raso... tem colocação que é fundo

AB137CF:36

TiNa colocação que pegava dois...

SM117CM:10

Seringal. sm. Área de terra onde tem uma determinada quantidade de colocações com estradas, seringueiros, patrão.

...mas o que acontece é que hoje o seringal tão tudo abandonado... num tem mercadoria...

TA087CM:13

(...)num quero mais é pó seringal não(...)

SM118CF:32

Eu morava lá... lá no seringal

MU153CM:113

\section{Conclusão}

Os dados apontam a presença marcante dos substantivos e verbos, por serem denotadores da ação do homem em nomear e fazer. Enquanto a utilização dos adjetivos e advérbios terminados em - mente é pouca entre os informantes.

Observou-se nas Zonas de Pesquisa estudadas, alteração fonética nas lexias: buião > bulhã; fornáia > fornalha; feche > fecho; juNio > Juno; setembo > setembro; hepatite > hapatite; quebrante > quebranto; remede > remédio; viziNo > vizim; arroiz > arroize; milho > mio; plantar > prantar; veado > viado; difíço > difícil, ocorrendo troca , acréscimo ou supressão de vogais ou consoantes.Com base nessas observações, é possível concluir que essas informações proporcionaram um contato com a vida do seringueiro, conhecendo o seu universo, através da linguagem. Depois, os dados apontam a unidade, a diversidade, a variação lexical e fonéticas nas áreas da Pesquisa, fornecendo dados que muito irão contribuir para o fechamento do Atlas Etnolinguístico do Acre - ALAC. 


\section{REFERÊNCIAS BIBLIOGRÁFICAS}

ALVAR, Manuel. La dialectologia. Madrid: 1963.

BRANDÃO, Silvia Figueiredo. A geografia linguística no Brasil. São Paulo: Ática, 1991.

COSERIU, Eugênio. O homem e sua linguagem. Rio de Janeiro: Presença, 1988.

CUNHA, Celso. Língua portuguesa e realidade brasileira. 4. ed. Rio de Janeiro: Tempo Brasileiro, 1988.

FERREIRA, Calota; CARDOSO, Suzana. A dialectologia no Brasil. Coleção "Repensando a língua portuguesa". São Paulo: Contexto, 1994.

LESSA, Luísa Galvão. Projeto Centro de Estudos Dialectológicos do Acre CEDAC. Comunicação apresentada no IX Congresso Internacional de Filosofia e Linguística da América Latina: ALFAL.

. Projeto Atlas Etnolinguístico do Acre - ALAC. Comunicação apresentada na V semana na UFMT. Cuiabá: 1992.

. Projeto Centro de Estudos Dialectológicos do Acre - CEDAC. A linguagem falada no vale do Purus. Rio de Janeiro: 2002 v. I

A linguagem falada no Vale do Acre - materiais para estudo. Centro de Estudos Dialectológicos do Acre - CEDAC, Rio de Janeiro, 2002.

. A linguagem falada no Vale do Juruá - materiais para estudo. Centro de Estudos Dialectológicos do Acre - CEDAC, Rio de Janeiro, 2002 .

. A linguagem falada no vale do Purus - materiais para estudo. Centro de Estudos Dialectológicos do Acre - CEDAC, Rio de Janeiro, 2002. 